\section{G148(P) DEFINING THE BURDEN OF PAEDIATRIC CARDIAC DISEASE IN MALAWI - THE EXPERIENCE FROM A TERTIARY REFERRAL CENTRE}

doi:10.1136/archdischild-2013-304107.160

'AMR Selman, ${ }^{1,2} \mathrm{~N}$ Kennedy, ${ }^{3,2}$ E Borgstein. 'Department of Paediatrics, Queen Elizabeth Central Hospital, Blantyre, Malawi; 'Department of Paediatrics, Malawi College of Medicine, Blantyre, Malawi; ${ }^{3}$ Department of Surgery, Queen Elizabeth Central Hospital, Blantyre, Malawi

Aim The literature relating to paediatric cardiac disease in subSaharan Africa is sparse and the spectrum of paediatric cardiac disease has not been described in Malawi.

A paediatric cardiology clinic with trans-thoracic echocardiography has been established in a tertiary referral hospital in Malawi since 2008. The clinic has collected data about the paediatric cardiac pathologies seen in this part of Malawi in an effort to better understand and modify their contribution to childhood morbidity and mortality.

Methods Between January 2009 and February 2011, the age and cardiac diagnosis of every child with an abnormal echocardiogram referred to the clinic was recorded in a database. The range of diagnoses is described.

Results Of 250 children, 139 (55.6\%) had congenital heart disease, and $111(44.4 \%)$ acquired heart disease. Ventricular septal defect (VSD) (24\%), Tetralogy of Fallot (10\%) and patent ductus arteriousus $(7.2 \%)$ were the commonest forms of congenital heart disease. Rheumatic heart disease (RHD) (22.4\%) and dilated cardiomyopathy $(13.6 \%)$ were the commonest acquired diseases. The mean age of presentation was 3 years 2 months for VSD and 11 years 6 months for RHD. For RHD, most present late and it is likely that untreated cardiac disease causes a large number of childhood deaths. The clinic provides secondary preventative treatment in the form of monthly benzathine penicillin injections. A total of 44 children have undergone cardiac surgery abroad in specialist centres in South Africa, India and Italy following referral from the clinic. Currently, surgical ligation of patent ductus arteriosus is offered by a specialist paediatric surgeon with 7 successful operations to date. Facilities and expertise do not allow for per-cutaneous catheterisation techniques or invasive cardiac surgery.

Conclusion In addition to the morbidity and mortality associated with congenital heart disease, children in Malawi face an additional significant burden of acquired heart disease - in particular rheumatic heart disease. Secondary prevention is an important part of ongoing treatment.

Adequate and accessible cardiothoracic surgical services should be established at a regional level to provide treatment for those amenable to surgery. Expanding charitable funding of surgery in specialist centres outside Malawi is an alternative in the meantime.

\section{G149(P) STROKE-RECURRENCE IN NIGERIAN CHILDREN WITH SICKLE CELL ANAEMIA TREATED WITH HYDROXYUREA AFTER A FIRST CLINICAL STROKE}

doi:10.1136/archdischild-2013-304107.161

IA Lagunju, BJ Brown, 0 Sodeinde. Department of Paediatrics, University of Ibadan, Ibadan, Nigeria

Background Chronic blood transfusion is the standard treatment for secondary stroke prevention in sickle cell anaemia (SCA) but this treatment option poses major challenges in resource-poor countries of the world, especially malaria-endemic ones.

Objective To compare the outcomes after a first clinical stroke, with and without treatment with hydroxyurea (HU).

Methods Over a 6-year period, Nigerian children with SCA who had suffered a first stroke was studied. Outcomes in those who received $\mathrm{HU}(25 \mathrm{mg} / \mathrm{kg} /$ day) were compared with those whose parents declined both HU and chronic transfusion.

Results Thirty-two children, all with haemoglobin SS phenotype (SCA) presented with stroke and one died of haemorrhagic stroke at presentation. Age at first clinical stroke (Mean +/- SD) was $7.58(+/-2.33)$ years. Thirteen children received HU while 18 declined HU therapy. The secondary stroke incidence of $7 / 100$ person years in the HU group was significantly lower than the $28 / 100$ person years in the non-HU group $(P=0.001$, OR 3.808 , $95 \%$ CI 1.556, 9.317). Children who did not receive HU were more likely to drop out of school and to have moderate-severe motor disabilities requiring caregiver assistance for activities of daily living.

Conclusion In settings where facilities for chronic blood transfusion are not accessible or feasible, HU therapy should be considered for secondary stroke prevention in children with SCA. Since, as far as we are aware, this is the first use of $\mathrm{HU}$ in a malaria-endemic setting, the possible impact of $\mathrm{HU}$ on drug-resistance in malaria needs to be carefully studied.

\section{REFERENCE}

1. Lagunju I, Sodeinde 0, Telfer P. Prevalence of transcranial Doppler abnormalities in Nigerian children with sickle cell disease. Am J Hematol. 2012 May; 87(5):544-7. doi: 10.1002/ajh.23152. Epub 2012 Mar 28. PubMed PMID: 22460323

Abstract G149(P) Table 1 Comparison of the demographics, clinical features and outcomes in the $\mathrm{HU}$ and non- $\mathrm{HU}$ groups

\begin{tabular}{llll}
\hline & $\begin{array}{l}\text { HU group } \\
(\mathbf{N}=\mathbf{1 3})\end{array}$ & $\begin{array}{l}\text { Non-HU group } \\
(\mathbf{N}=\mathbf{1 8})\end{array}$ & P-value \\
\hline $\begin{array}{l}\text { Mean follow-up time after first stroke in years } \\
\text { (SD) }\end{array}$ & $2.6(1.2)$ & $2.5(1.1)$ & 0.896 \\
Stroke recurrence & 7 & 28 & 0.001 \\
$\begin{array}{l}\text { Incidence of stroke recurrence/100 } \\
\text { person-years }\end{array}$ & 15.4 & 77.8 & 0.001 \\
Stroke recurrence (\%) & 145 & 140 & 0.175 \\
Mean time to stroke-recurrence (months) & & & \\
$\begin{array}{l}\text { Outcome at end of follow up period } \\
\text { Moderate-Severe motor disability }\end{array}$ & $\mathrm{N}(\%)$ & $\mathrm{N}(\%)$ & $<0.001$ \\
$\begin{array}{l}\text { Drop-out from school } \\
\text { Epilepsy }\end{array}$ & $3(23.1)$ & $16(88.9)$ & 0.003 \\
Learning difficulties & $3(7.7)$ & $11(61.1)$ & 0.499 \\
\hline
\end{tabular}

\section{G150(P) IS THE ETAT+ COURSE EFFECTIVE IN REDUCING MORTALITY IN CHILDREN WITH MALNUTRITION IN A TERTIARY AND DISTRICT HOSPITAL, RWANDA?}

doi:10.1136/archdischild-2013-304107.162

${ }^{1} \mathrm{PT}$ Cartledge, ${ }^{2} \mathrm{~T}$ Lissauer, ${ }^{3} \mathrm{~L}$ Tuyisenge. 'Yorkshire School of Paediatrics, Yorkshire Deanery, Leeds, UK; ${ }^{2}$ Institute of Global Health, Imperial College, London, UK; ${ }^{3}$ Paediatrics, Kigali University Teaching Hospital, Kigali, Rwanda

Aims The Emergency, Triage, Assessment and Treatment plus Admission (ETAT + ) course has incorporated the World Health Organization's (WHO) 10 steps for the management of malnutrition. ${ }^{12}$ The ETAT + course was implemented in two urban Rwandan hospitals. A tertiary hospital from October 2010 and a district hospital from March 2011. The aim of this audit was to assess if the teaching and implementation of the ETAT + course has successfully reduced mortality rates in in children (between 2 months and 5 years of age) with malnutrition.

Methods The medical records, discharge summaries, and death certificates of all the 429 children with malnutrition, admitted to these two hospitals between March 2008 and November 2011 were retrospectively reviewed and analysed using SPSS.

Results We reviewed the notes of 337 children pre ETAT + of whom 37 died (11\%) compared with 84 post-ETAT of whom 2 died (2.4\%). 